\title{
$\mathfrak{j} \mathfrak{h} \mathfrak{a} \mathfrak{l} \mathfrak{t}$
}

\section{Erftes Seft.}

Die bentide Sprndjeintyeit. (Whilferm Sdyerer.) . . . . . . . . . . Seite 1

Şerber unb Beorg Milller. (Fg. Baumgnten.) . . . . . . . . . . - 23

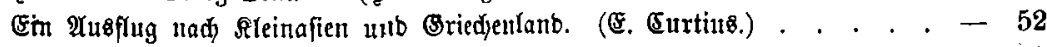

StaYien unb Mom. (.. Sartwig.) . . . . . . . . . . . . . . - 72

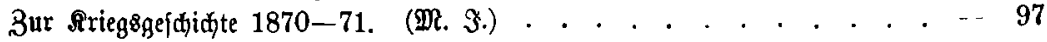

Eanzleiftil ans ben napoleonifden Tagen. (ફ. ๖. $\mathfrak{T}$ ) . . . . . . . . -103

Foltitide Eorrejponbenz. . . . . . . . . . . . . . . . . . . -110

Rotigen. . . . . . . . . . . . . . . . . . . . . . -122

\section{3weite sef seft.}

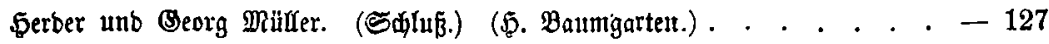

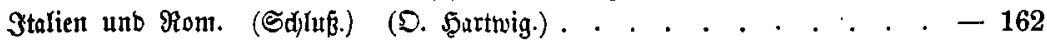

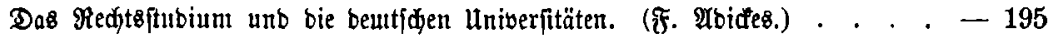

ueber ben Begriff ber politifjem Freibeit. (Friebrid Thubidum.) . . . . -215

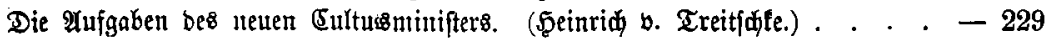

$\mathfrak{A} u \mathfrak{B}$ Bien. . . . . . . . . . . . . . . . . . . . . . . -240

Bolitijđe Correfpontentz. . . . . . . . . . . . . . . . . . . -243

Rotizen. . . . . . . . . . . . . . . . . . . . . . . . -252

\section{Dritte $\mathfrak{\$}$ eft.}

Der Spradjen $=$ unb Raffenftreit in $\mathfrak{B e l g i e n . ~ ( F r . ~ D e t f e r . ) ~ . ~ . ~ . ~ . ~ . ~ . ~ - ~} 257$

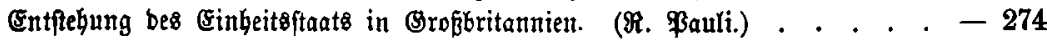

Die Entftehung ber amerifaniføen union. (\$. von \$olft.) . . . . . . - 292

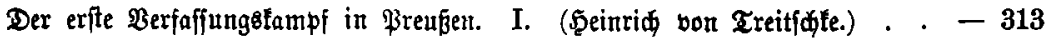

Ein neuer Beitrag zur Befdidte bes Sirieges bon 1870-71. (․ $\mathfrak{x}$.$) . . - 360$

ßolitifige Eorrefponbenz. (d.) . . . . . . . . . . . . . . . . -369

Notizen. . . . . . . . . . . . . . . . . . . . . -376 


\section{Bierte פeft.}

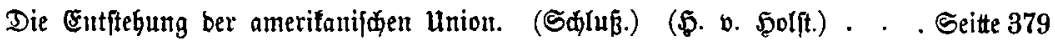

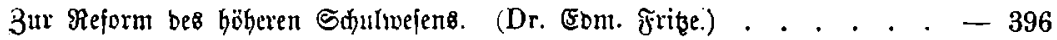

Der erfte Berfaffumggtampf in Preußen. II. (Şeimrid von Treitjdfe.) . . 409

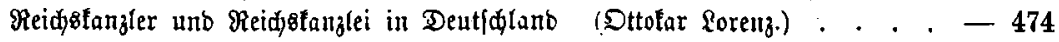
Bon Berliner Mujeum. (隹ze.) . . . . . . . . . . . . . . - 506

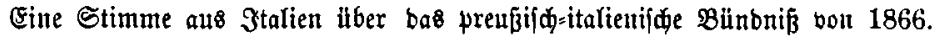

(ङ. Эacini.) . . . . . . . . . . . . . . . . . . . . -513 Bolitifdue Eorrejponbenz. (d.) . . . . . . . . . . . . . . . . -541 Preisaufgaben ber Kubenow=Stiftung. . . . . . . . . . . . . . -551

\section{Finfinfes beft.}

3ur Erimterung an meitten Bater. (Ernft Эnmanuel Befter.) . . . . . - 553

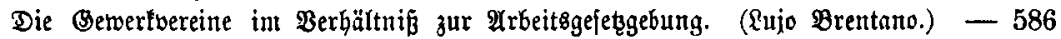
Sorb Buron. (\$erberg.) . . . . . . . . . . . . . . . . - 601

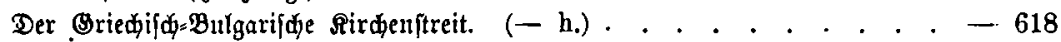

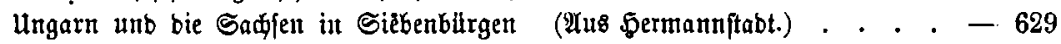

Sediftez Şeft.

3ur Erinnerung an meinen $\mathfrak{B a t e r . ~ ( S d f u p ̉ ) ~ ( E r n f t ~ \Im m m a n u e l ~ B e f f e r . ) ~ . ~ - ~} 641$

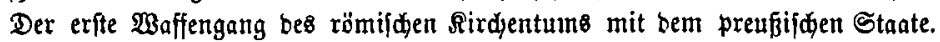

(\&ic. Dr. Theodor Brieger.) . . . . . . . . . . . . . . . -669

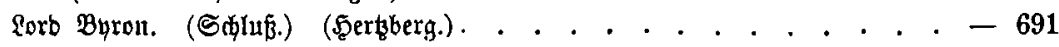

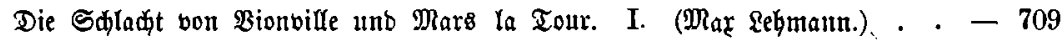

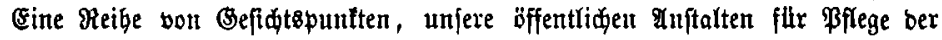

Runft betreffent. (\$erman (Brintm.) . . . . . . . . . . . - 747 Politifde Eorrefponbenz. . . . . . . . . . . . . . . . . -756 